\title{
Emergency ambulance speed characteristics: a case study of Lesser Poland voivodeship, southern Poland
}

\author{
Michał Lupa ${ }^{1} \cdot$ Monika Chuchro $^{1} \cdot$ Wojciech Sarlej ${ }^{1} \cdot$ Katarzyna Adamek $^{1}$ (D)
}

Received: 22 November 2019 / Revised: 21 May 2021 / Accepted: 14 July 2021 /

Published online: 13 August 2021

(C) The Author(s) 2021

\begin{abstract}
The correct estimation of ambulance travel time is an extremely important issue from the perspective of healthcare and the security of citizens. In some events, the threat to the health or life of an injured person increases with each minute of waiting for an ambulance. The authors of this article analyzed how ambulances travel throughout the entire Lesser Poland voivodeship in southern Poland. Based on the analysis of 300 million GPS records that were collected over several years from 300 ambulances, real ambulance speed characteristics were compiled for the most important cities in the region. The obtained results regarding ambulance speed characteristics were used to understand the correlation between ambulance speed, the density of the road network, and the built-up areas of a given city. Furthermore, the impact on the speed of ambulances of traffic, time of day, day of the week, or the season was also examined. The influence of the use of ambulances' lights/ sirens on travel time was also examined. The culmination of the research was the presentation of the theoretical foundations of coverage maps and a method of implementing them based on the determined speed characteristics. The presented studies show that the speed at which ambulances move is a very local phenomenon. Also, a relatively constant average speed of ambulances throughout the whole week was found. Moreover, a difference in speed between signaled and non-signaled ambulance trips was observed. The speed characteristics that were obtained were used as input data for the development of dynamic coverage maps, which are an invaluable tool for supporting the decisions of ambulance dispatchers.
\end{abstract}

Keywords Emergency $\cdot$ Ambulance response time $\cdot$ Coverage maps $\cdot$ GIS

Katarzyna Adamek

kadamek@agh.edu.pl

Michał Lupa

mlupa@agh.edu.pl

Monika Chuchro

chuchro@agh.edu.pl

Wojciech Sarlej

wsarlej@agh.edu.pl

1 Department of Geoinformatics and Applied Computer Science, AGH University of Science and Technology, Mickiewicza 30, 30-059 Kraków, Poland 


\section{Introduction}

Emergency medical services (EMS) are widely considered to play one of the most important roles in healthcare systems, but time is a vital factor in saving the health or life of patients to whom an ambulance has been called. In Poland, the statutory arrival time is defined by relevant government directives [1]: it is up to $15 \mathrm{~min}$ in urban areas and up to $20 \mathrm{~min}$ in rural areas. Reducing ambulance travel time and understanding its effects is therefore an extremely important issue.

Models and their parameters related to the planning and management of ambulance journeys have become a critical issue for the efficiency of EMS, as demonstrated by [2]. It seems reasonable that the first of the considered elements is routing itself. The issue of determining travel routes and travel time estimations concerns not only ambulances but is also a common subject of discussion [3-6]. In the case of ambulances, the route can be calculated with many different algorithms that also take into account other more specific conditions. Attention was also drawn to this problem by [7]. The need for solutions more suited to ambulances was also signaled by [8-10]. A growing body of literature has examined many different factors, including the significance of the use of lights and sirens by ambulances.

Emergency service vehicles are privileged when they are using light and sound signals, so their travel time from point A to B may differ from a civil vehicle. An attempt was made almost 25 years ago [11] to determine these differences as part of a study that was conducted in a city of 46,000 residents in the United States. As Hunt et al.'s research showed, the average difference between ambulance travel time with lights/sirens on compared to off was $43.5 \mathrm{~s}$. The conclusion was that driving with signals on does not offer a significant advantage and is unnecessary. The authors recommended that signals should be used only rarely or in emergency situations. Another study that was carried out 5 years later [12] indicated a difference between signaled and unsignaled rides of $1 \mathrm{~min}$ and $46 \mathrm{~s}$ on average. In this case, the studied area was a city with a population of over 170,000 residents. Similar research was also done by [13], which showed that rides with signals were around 3 min $2 \mathrm{~s}$ faster, therefore the authors considered this a significant reason for driving with signals on. It should be mentioned that in this case the travel times were measured for a city with more than 370,000 residents. Two conclusions can be drawn from the aforementioned studies: firstly, ambulance travel time varies according to the size and population of a city; secondly, the use of light and sound signals allows ambulance travel time to be reduced by varying amounts. Nonetheless, the other conclusions that were reached by [14] showed that ambulances using priority signals are on average $2.9 \mathrm{~min}$ faster in urban areas and $8.9 \mathrm{~min}$ faster in rural areas. This suggests that research results are strongly dependent on the local environment.

A key problem with much of the aforementioned literature is that it was carried out over 20 years ago, but a lot has changed since then. Over the last two decades, the number of cars in the world has increased dramatically. According to the International Organization of Motor Vehicle Manufacturers, car sales between 2005 and 2018 increased by almost 1/3 and currently exceed 97 million vehicles a year. The Polish Association of Automotive Industry statistics shows that around 30 million vehicles were registered between 1990 and 2017 in the Lesser Poland voivodeship, and Cracow, which is considered in this article and is the largest city in the province, is the 26th most congested city in the world with a $40 \%$ congestion level according to the TomTom Traffic Index [15]. The increase in the number of cars has caused 
traffic jams and a dramatic decrease in road capacity. This is confirmed by an article in which the authors analyzed ambulance travel times in Singapore [16], and nowadays this is one of the most important problems affecting emergency service vehicles. Many factors were analyzed, but the aforementioned researchers found that traffic levels, weather (heavy rainfall) and incident location (on the street or at a patient's home) were statistically significant. However, the factors that determine response times can also be location dependent: for example, factors relevant to the UK may be of little importance in Singapore. As shown in [17], when the average daily air temperature drops below $2{ }^{\circ} \mathrm{C}$ or rises above $20{ }^{\circ} \mathrm{C}$, ambulance response times increase. This is due to the higher number of calls in summer and winter, as well as the deterioration of road conditions when the temperature is low. Moreover, several studies have shown that air pollution has a significant impact on ambulance call-out incidents [18-20]. These studies also lead to the conclusion that the management of ambulance fleets must consider a variety of local factors.

The characteristics of the road network itself and of current and predicted traffic are also important components of the decision model [21]. Some solutions based on network models are applicable to logistics, with particular emphasis on the Vehicle Routing Problem [22, 23]. Currently, tools use genetic algorithms to statically optimize the deployment of ambulances in relation to the current demographic structure of a given city. However, due to the continuous increase of urbanization, these algorithms take into account constant changes in the demographic distribution of cities and allow for the dynamic relocation of ambulances according to current needs [24]. Additionally, one of the most interesting tools that supports ambulances is coverage maps. In [25-27] some interesting applications of coverage maps are described that show the potential duration of an ambulance's passage to a given place. Other examples include the analysis of vaccine coverage maps [28], as well as systems that support decisions regarding the distribution of patients in hospitals for special purposes [29]. However, the above considerations carry an element of uncertainty. Statistical data and computer simulations may contain errors that affect estimation results. As shown in the paper [30], average predicted ambulance journey time was underestimated by $1.6 \mathrm{~min}$, which was statistically significant.

This discussion raises many questions regarding determining the local factors that seem to be significant for minimizing errors in the estimation of trip times with an appropriate model of ambulance speeds. Understanding that how ambulances move is highly dependent on local conditions and is not the same as how civil vehicles move indicates that the speed models embedded in commercial or open-source software may differ from ambulances' actual movement patterns in a given locality. This in turn may lead to underestimation or overestimation of ambulance travel times.

This paper sheds new light on what local factors might be determined for the cities and towns of southern Poland. The importance of whether an ambulance is signaled (S) or unsignaled (T) was upheld in accordance with previous findings in the literature. The average speed of signaled ambulances, the impact of the time of day, day of week or time of year was analyzed, and no significant influence was found in the analysis of individual towns and cities. Nevertheless, these constant speeds vary between localities and might be related to local characteristics such as road infrastructure and building or road density. This paper investigates (1) whether ambulance speed can be uniform for a locality; (2) if there are groups of similar velocities; (3) what factors determine which city belongs to which group. 


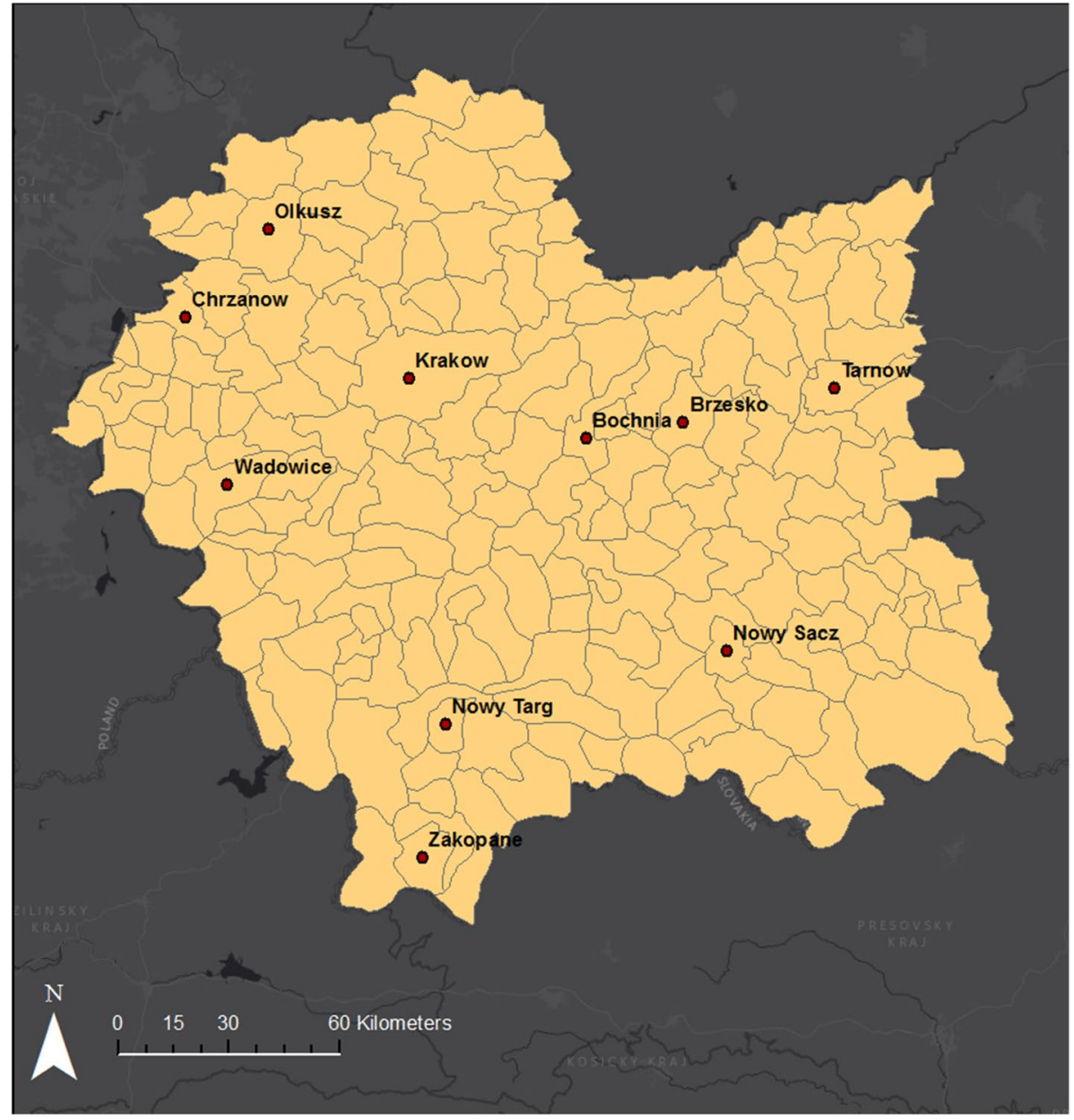

Fig. 1 The borders of the Lesser Poland voivodship; the selected cities which were studied are shown

\section{Experiments}

The following chapter consists of two parts: the first is a detailed description of the dataset used to determine the speed characteristics of ambulances; the second part covers the analysis, in which the speed of non-emergency (i.e. without sirens/lights) trips, ambulance calls, differences in day, week, month and year are compared. Moreover, this comparison also shows average ambulance speeds for individual cities in the voivodship. The intention of the authors was to check whether these speed characteristics would be uniform for the entire Lesser Poland voivodship (Fig. 1). 
Table 1 Number of records for individual cities

\begin{tabular}{llc}
\hline No & City & $\begin{array}{l}\text { Number } \\
\text { of records } \\
\text { [Mill.] }\end{array}$ \\
\hline 1 & Bochnia & 5.8 \\
2 & Brzesko & 4.5 \\
3 & Chrzanow & 9.4 \\
4 & Krakow & 180.2 \\
5 & Nowy Sacz & 15.4 \\
6 & Nowy Targ & 12.3 \\
7 & Olkusz & 9.5 \\
8 & Tarnow & 20.1 \\
9 & Wadowice & 10.3 \\
10 & Zakopane & 12.8 \\
\hline
\end{tabular}

\subsection{Dataset}

Continuously collected data is required to determine long-term ambulance characteristics. Furthermore, the data set must refer to all possible ambulances moving in the area as this makes it possible to reduce factors that may cause noise, such as drivers' skills or individual vehicles' characteristics. In view of the above assumptions, data collected in 2011-2017 by the Cracow Rescue Service was obtained. These data were part of the medical emergencies decision-support system and consist of emergency calls and notification details, medical emergency teams' management decisions, medical event records and the location of individual incidents. Data was collected in the main cities of Lesser Poland voivodship (see Fig. 1) from a total of 300 ambulances.

This information was added to a database with over 280 million records. A single tuple was a single read from the GPS in an ambulance which sent information about its location to the server. Data was provided every minute by each ambulance on standby; every $30 \mathrm{~s}$ for unsignaled ambulances; and every $15 \mathrm{~s}$ when driving to an emergency call. In addition to coordinates stored in the Well-Known Binary (WKB) [31] format, the table also contains information about time, speed, or trip status (emergency or non-emergency) and road type. Initially, data was divided into 10 city groups without suburban areas. Table 1 presents the locations along with the number of records.

\subsection{Analysis}

The research hypothesis was that the model parameters are stable for particular locations, regardless of day of the week, hour, etc. In other words, the experiments were carried out to establish whether ambulances move at the same speed, regardless of the time of day, day of week and time of year.

\subsubsection{General statistics}

The initial phase of the experiments included analysis of mean ambulance speeds for a given day of the week. Two types of trips were considered. The first, marked with the $S$ (Signal on) prefix, includes ambulances with light or sound signals on. The second variant, 
Table 2 Selected descriptive statistics

\begin{tabular}{|c|c|c|c|c|c|c|c|c|c|}
\hline \multirow[t]{2}{*}{ No } & \multirow[t]{2}{*}{ City } & \multicolumn{4}{|c|}{$\mathrm{T}[\mathrm{km} / \mathrm{h}]$} & \multicolumn{4}{|c|}{$\mathrm{S}[\mathrm{km} / \mathrm{h}]$} \\
\hline & & mean & $\min$ & $\max$ & $\mathrm{sd}$ & mean & $\min$ & $\max$ & $\mathrm{sd}$ \\
\hline 1 & Bochnia & 37.1 & 35.7 & 39.1 & 1.04 & 60.5 & 59.5 & 61.8 & 0.92 \\
\hline 2 & Brzesko & 39.7 & 38.4 & 42.3 & 1.37 & 61.7 & 60.8 & 63.7 & 1.04 \\
\hline 3 & Chrzanow & 33.5 & 31.3 & 36.8 & 2.04 & 53.4 & 52.7 & 54.7 & 0.68 \\
\hline 4 & Krakow & 34.1 & 32.8 & 36.6 & 1.57 & 48.8 & 47.9 & 50.0 & 0.84 \\
\hline 5 & Nowy Sacz & 29.8 & 28.5 & 32.7 & 1.53 & 50.6 & 49.2 & 52.9 & 1.47 \\
\hline 6 & Nowy Targ & 37.3 & 36.3 & 39.1 & 0.91 & 51.0 & 50.3 & 51.8 & 0.48 \\
\hline 7 & Olkusz & 43.2 & 41.7 & 46.1 & 1.47 & 62.8 & 61.5 & 64.4 & 1.20 \\
\hline 8 & Tarnow & 38.6 & 36.5 & 42.1 & 2.20 & 60.4 & 59.6 & 63.0 & 1.27 \\
\hline 9 & Wadowice & 36.4 & 34.5 & 40.8 & 2.23 & 60.0 & 59.0 & 61.7 & 1.10 \\
\hline 10 & Zakopane & 28.5 & 27.5 & 30.4 & 1.00 & 47.6 & 46.8 & 48.2 & 0.55 \\
\hline
\end{tabular}

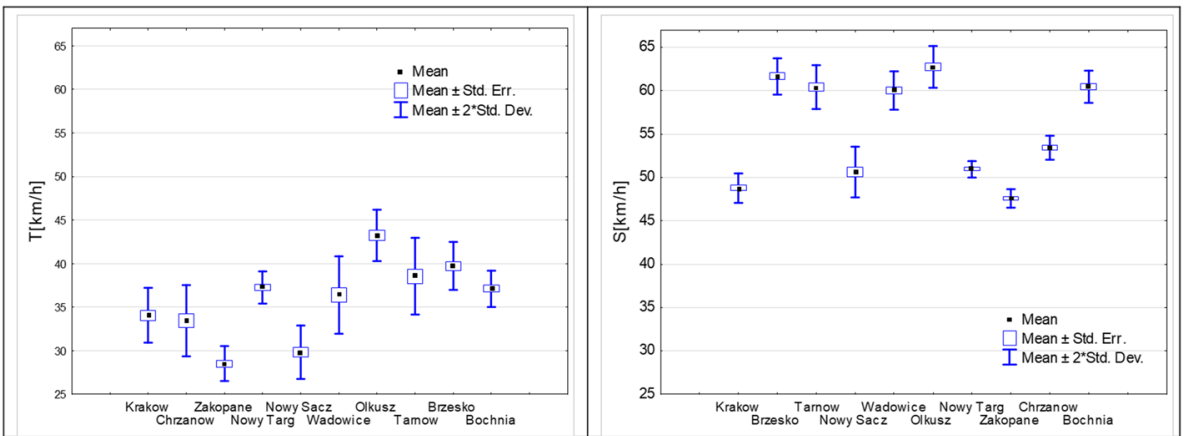

Fig. 2 Average speeds of ambulances without signal (a) and with signal (b)

designated with the T prefix (no signals/non-urgent trip), concerned ambulance trips without signaling enabled. Basic descriptive statistics showing differences in vehicle speed are presented in Table 2.

The speed of ambulances using signals (S) is on average $56 \%$ higher than ambulances driving without a signal (T), with the lowest difference observed in Nowy Targ (37\%) and the highest in Nowy Sacz (70\%). It is interesting that the standard deviation is lower for ambulances driving with a signal than for those without. Considering descriptive statistics for ambulances driving with lights/sirens, there is a visible division into towns with lower speeds (Chrzanow, Krakow, Nowy Sacz, Nowy Targ and Zakopane) and higher speeds (Bochnia, Brzesko, Olkusz, Tarnow, Wadowice). Differences in traveling speeds and their standard deviation are shown in Fig. 2.

\subsubsection{Day of the week}

The grouped mean speeds for individual days of the week are shown in the graph below (Fig. 3). The visible and expected conclusion is the partitioning into two speed groups according to the type of ambulance trip (first—signals on (S), second — signals off (T)). Average speed variations in these two groups are significant and are as much as $20 \mathrm{~km} / \mathrm{h}$. 


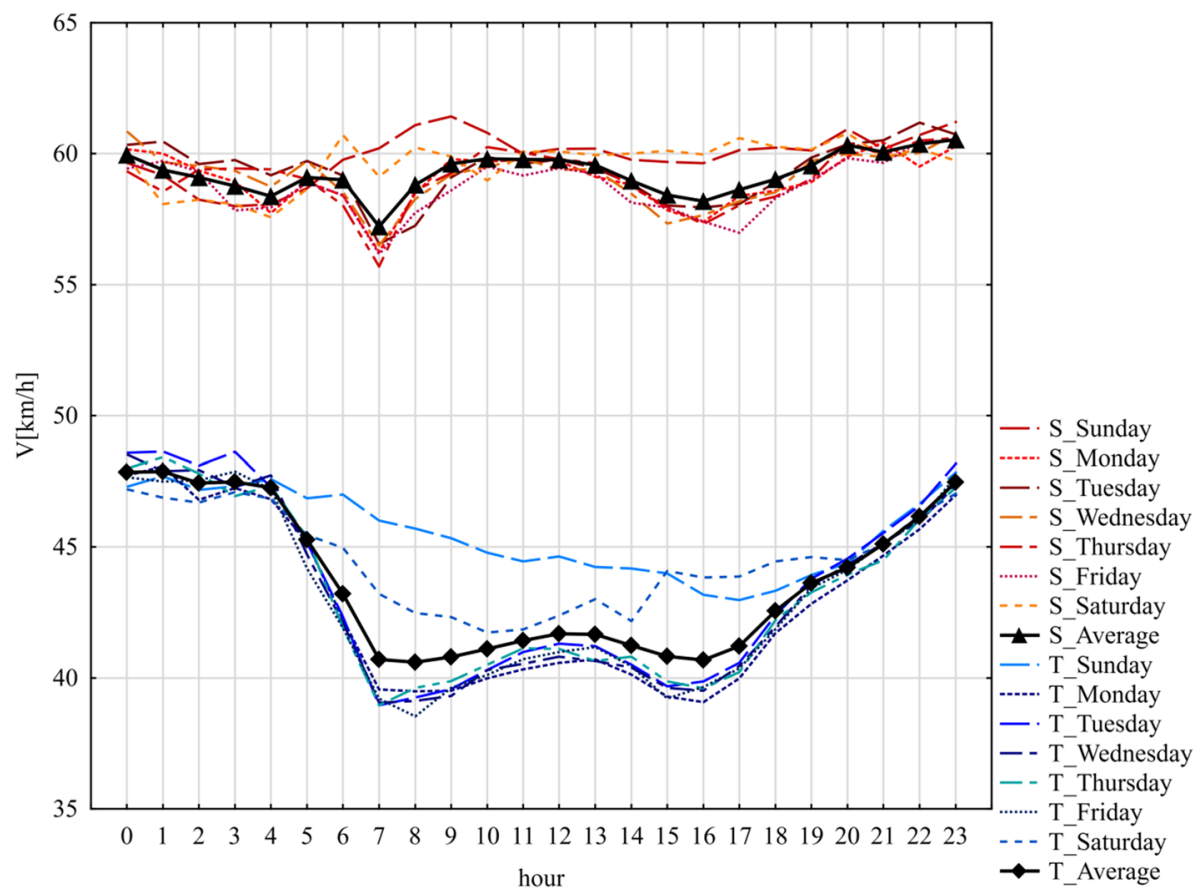

Fig. 3 Average ambulance speed for the entire voivodship by day of the week

In the case of trips with enabled signaling (S), it can be seen that the speeds are relatively constant, regardless of the day of the week. Moreover, by analyzing the following curves depending on the time of day, a speed collapse might be noticed at around 7 am that is related to increased commuter traffic. Although the average speed during these hours is the lowest, the actual decrease is only $2.5 \mathrm{~km} / \mathrm{h}$, which is insignificant. A difference in speeds was also observed at weekends: on Sunday mornings, speeds differ by about $5 \mathrm{~km} / \mathrm{h}$ in relation to working days (Sunday is marked with a dashed line). In the context of the whole week, these differences are not significant and are within the statistical margin of error. The above assumptions make it possible to conclude that ambulances using lights/sirens move at a relatively constant average speed.

More support for this thesis could be observed in the speed characteristics of nonurgent journeys (T), which show how ambulances move during the day. As in the case of trips with signals on (S), a noticeable drop in speed can be seen at around $7 \mathrm{am}$; however, in this case the impact of traffic is much more evident because the speed differences are around $10 \mathrm{~km} / \mathrm{h}$. There is also a disproportion between working days and Sundays, which have a distinctly different speed profile due to the lack of traffic jams in the morning. This speed characteristic is not constant; the independent variable is the time of day.

Nevertheless, the use of ambulance time coverage maps in dispatch decision support relates to trips with lights/sirens in the vast majority of cases. Therefore, to determine ambulances' speed characteristics, only curves from the first group (prefix S-Signal on) were selected. The apparent difference between trip types is a result of ambulances' road privileges and their use of the bus lanes (designated for public transport and emergency vehicles with signals on) that exist in larger cities. Therefore, the first part of the analysis 
Table 3 Two-way ANOVA for the entire voivodship speed by day of the week with Scheffé's test

\begin{tabular}{llllllll}
\hline & SS & $\begin{array}{l}\text { Degr. of } \\
\text { Freedom }\end{array}$ & MS & F & $p$ & \multicolumn{2}{l}{ Scheffe's test } \\
\cline { 3 - 7 } & & & & Effect & $p$ \\
\hline Intercept & 36,357 & 1 & 36,357 & 166,228 & 0.000 & & \\
Day of the week & 11.49 & 6 & 1.92 & 8.8 & 0.009 & Friday-Sunday & 0.03 \\
S/T & 1062 & 1 & 1062 & 4855 & 0.000 & S-T & 0.00 \\
Error & 1.31 & 6 & 0.22 & & & & \\
\hline
\end{tabular}

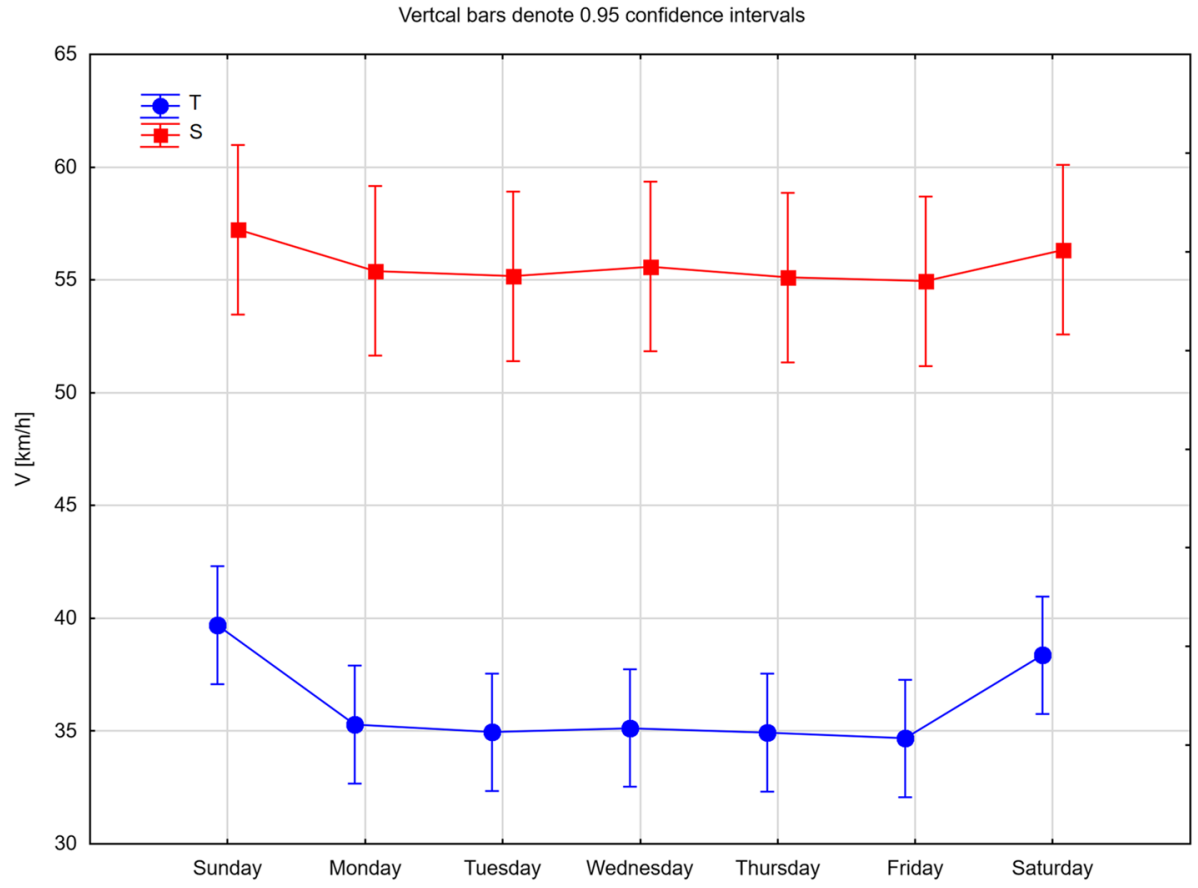

Fig. 4 Two-way ANOVA for ambulance speeds across the entire voivodship by day of the week

shows that the speed characteristics are stable if we only analyze the impact of the day of the week and disregard all other factors.

The Student's T-test and two-way analysis of variance (ANOVA) were used to determine whether any of the differences between the means ( $\mathrm{S}$ and $\mathrm{T}$ ) are statistically significant [32]. The significance level used in analysis was 0.05 , therefore this indicates a 5\% risk of concluding that a difference exists when there is no actual difference. ANOVA results are presented in Table 3 and in the graph below (Fig. 4).

The $\mathrm{p}$ value of the analysis is less than the significance level, so the null hypothesis is rejected and not all population means are equal (see Table 3). With a post hoc Scheffé's test, we can conclude that the difference between ambulance speed on signal (S) and without signal (T) is statistically significant. Also, we can observe a statistically significant difference between mean speed data divided by day of the week (see Table 3 and Fig. 4). The post hoc Scheffé's test is the most rigorous post hoc test, and it confirmed the existence of a 


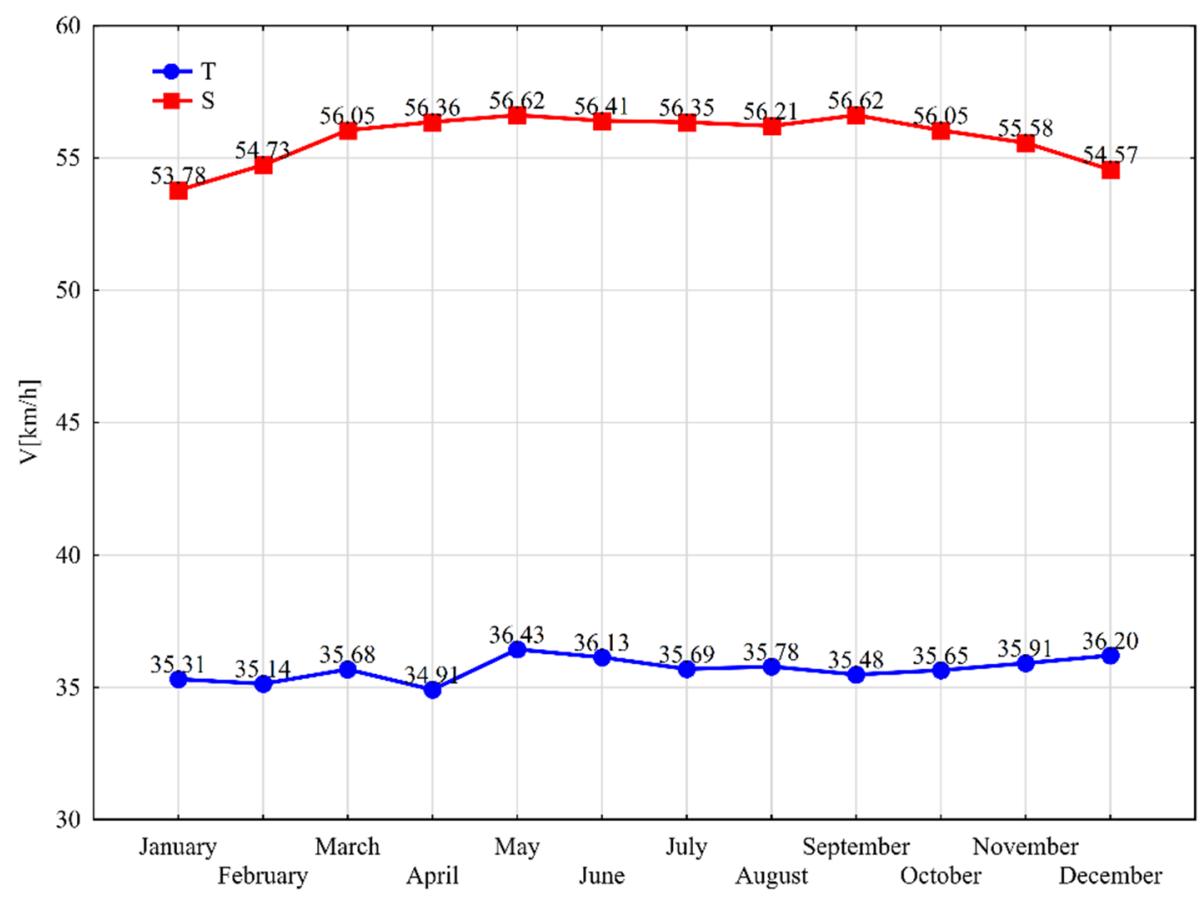

Fig. 5 Average ambulance speed for the entire voivodship by month

statistically significant difference between Friday and Sunday. Therefore, these results can lead to the conclusion that ambulance speed depends on the type of trip and the day of the week in case of unsignaled trips (Fig. 4).

\subsubsection{Season and year}

The second part of the hypothesis is that the parameters of the data model are stable, regardless of the time of the year (month). In order to verify the assumptions, the speeds for individual months are calculated, and the trips are divided into emergency calls (signal on) and non-urgent trips. The results are shown in the graph below (Fig. 5).

By comparing speeds in the winter months (December, January, February, March) we can see that speeds are lower than in the other months. Furthermore, higher speeds in warmer months (April to October) can be observed, and one month (November) is different to all the other months. The biggest difference in speed is between January and July $(4.17 \mathrm{~km} / \mathrm{h})$ and is caused by extreme road conditions. Nevertheless, these variations are also within the margin of error, thus allowing the impact of seasons on the speed of ambulances to be disregarded. When analyzing the speed of ambulances when driving without signals, there is no visible tendency similar to that presented above. Differences in speeds are no more than $1.5 \mathrm{~km} / \mathrm{h}$, with the lowest speed in April and the highest in May.

Therefore, the next part of the hypothesis is also confirmed. The authors also analyzed ambulance speeds in the 2011-2017 period. The diagram (Fig. 6) shows that the observed average speed fluctuations are up to $1.48 \mathrm{~km} / \mathrm{h}$ for ambulances on signal, with a small decrease in recent years. Average speeds do not exceed the margin of error, thus showing 


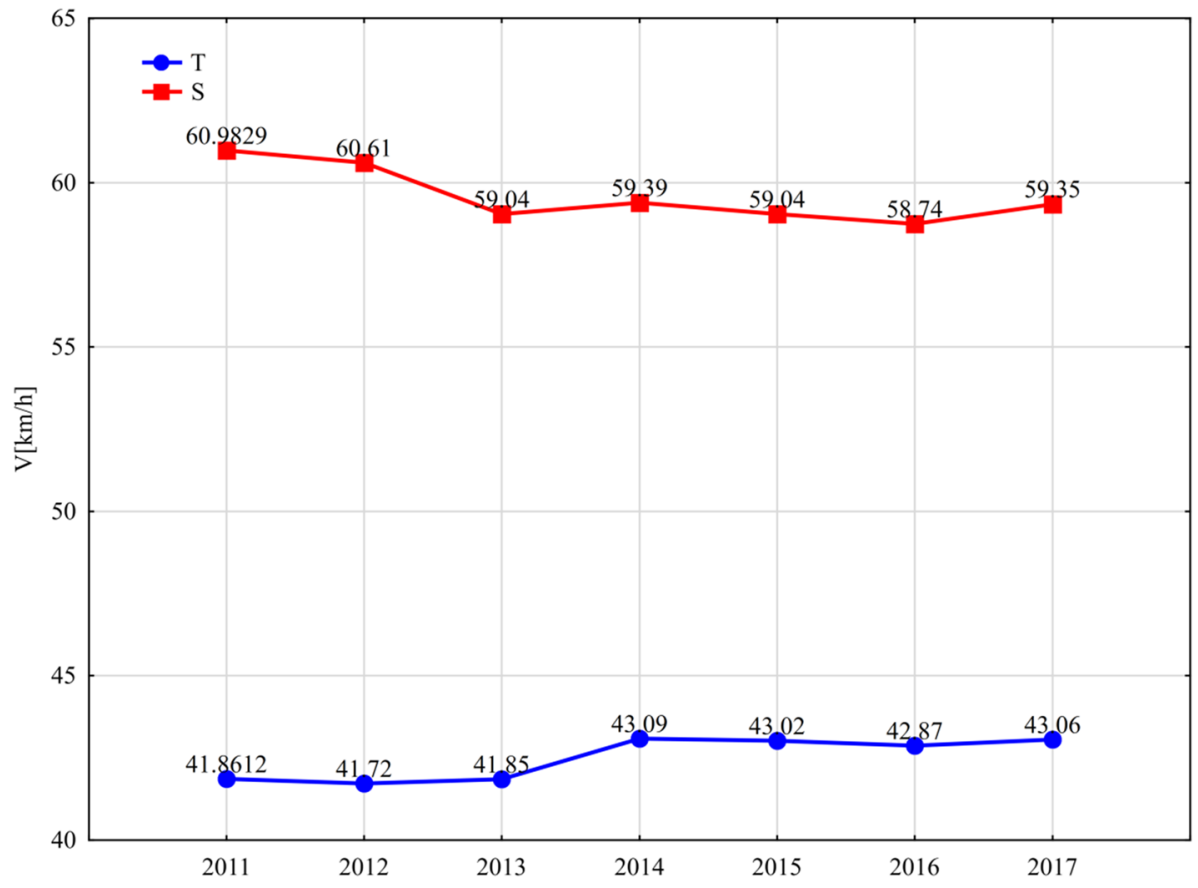

Fig. 6 Average ambulance speed for the entire voivodship between 2011 and 2017

that in the last 5 years there have been no significant modifications to the infrastructure, ambulance fleet, or traffic regulations. This interesting change in speeds is visible for vehicles moving without signal. The graph shows that there is a very weak positive tendency in the data that is statistically non-significant over this short period of time.

The two-way ANOVA confirmed the information shown in Figs. 5 and 6. There is no statistically significant difference between years and months.

\subsubsection{Characteristics in particular cities}

The second part of the hypothesis concerns the stability of the model in each city of the voivodship. Verifying that the ambulances moved at a constant speed irrespective of locality would then represent a confirmation of the initial assumption. Accordingly, 10 cities in Lesser Poland of different sizes, features, population density and road infrastructure were analyzed. The analysis was mainly based on the speed of trips with signals on; the results are shown in the diagram below (Fig. 7).

This chart (Fig. 7) clearly shows the division of curves into two groups. Let us call them faster (red curves) and slower (blue) curves. The difference in average speed for both groups is about $10 \mathrm{~km} / \mathrm{h}$ in all months. In the case of individual cities, the speeds differ by as much as $21 \mathrm{~km} / \mathrm{h}$, as can be observed in February between Zakopane and Olkusz. It was assumed that the two speed characteristics are a result of city functions and the road network. The faster group contains cities where tourist traffic is rather negligible. Bochnia, Brzesko, Olkusz, Tarnow and Wadowice are typical industrial transit 


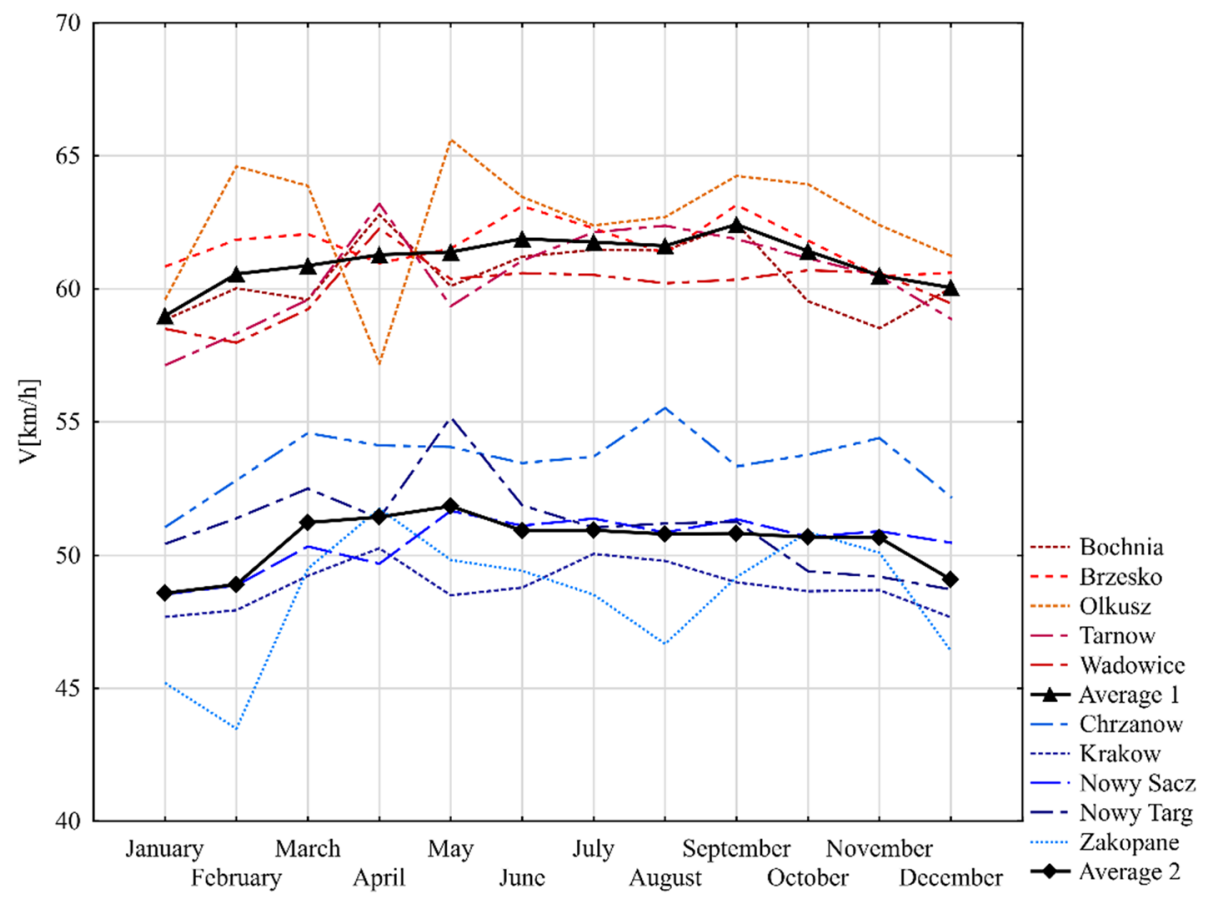

Fig. 7 Average ambulance speeds for selected Lesser Poland cities, grouped by month

cities with well-developed road infrastructure and average speeds above $60 \mathrm{~km} / \mathrm{h}$ for ambulances moving with signals on (Table 2).

Except for Chrzanow, the slower group (average speed below $54 \mathrm{~km} / \mathrm{h}$ ) includes cities with more tourist traffic, especially in the winter months. In the case of Chrzanow, the density of the road network is decisive; this conclusion is confirmed by the fact that Chrzanow is in the vicinity of the city of Olkusz, where ambulances are fastest, and both towns serve as industrial cities. Moreover, the graph of the speed of non-urgent trips (Fig. 8) seems to confirm these observations. The only exception is the city of Nowy Targ, where the speed of trips without signals was comparable to the lower speed range of the faster group.

The adopted methodology also required a speed comparison compiled by the day of the week and hour of the day. Therefore, the collected values for the selected cities are shown in the graphs (Figs. 9, 10). By analyzing the speed during the week, the breakdown into two groups is even more visible than in Fig. 7, and the average speed difference is around $11 \mathrm{~km} / \mathrm{h}$. In the case of hourly comparison, speed fluctuations are more varied; however, both the average velocity difference and the general characteristics of the two groups are preserved.

In order to confirm the visual division into two groups, cluster analysis was performed using the k-means method and the agglomeration method [33, 34]. Cluster analysis using k-means was carried out with V-fold cross validation [35] in order to determine the optimal number of clusters. The algorithm divided the data into 2 clusters according to the visual division of data. The distance of clusters from each other and individual cities from the cluster center indicates a very clear division of data (Table 4). 


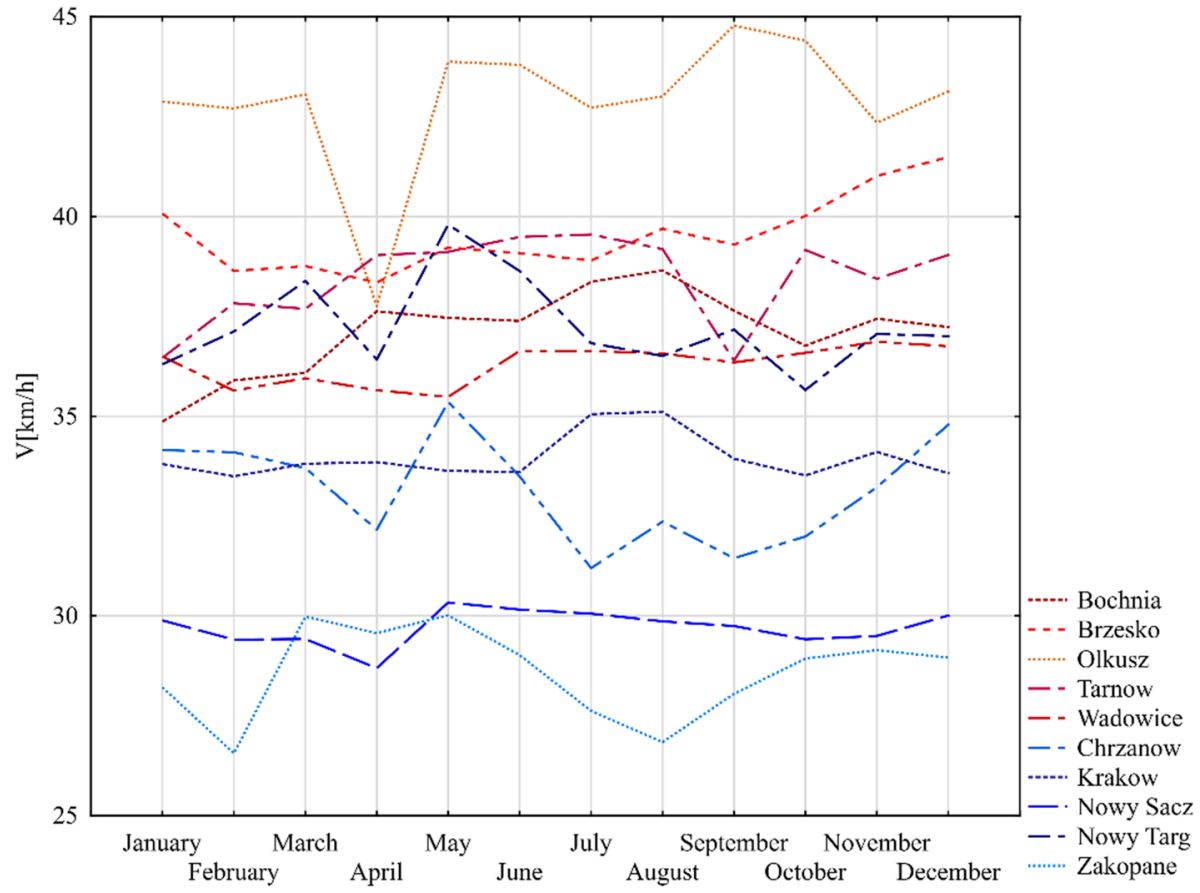

Fig. 8 Average speed of ambulance trips without signals for selected Lesser Poland cities, grouped by month

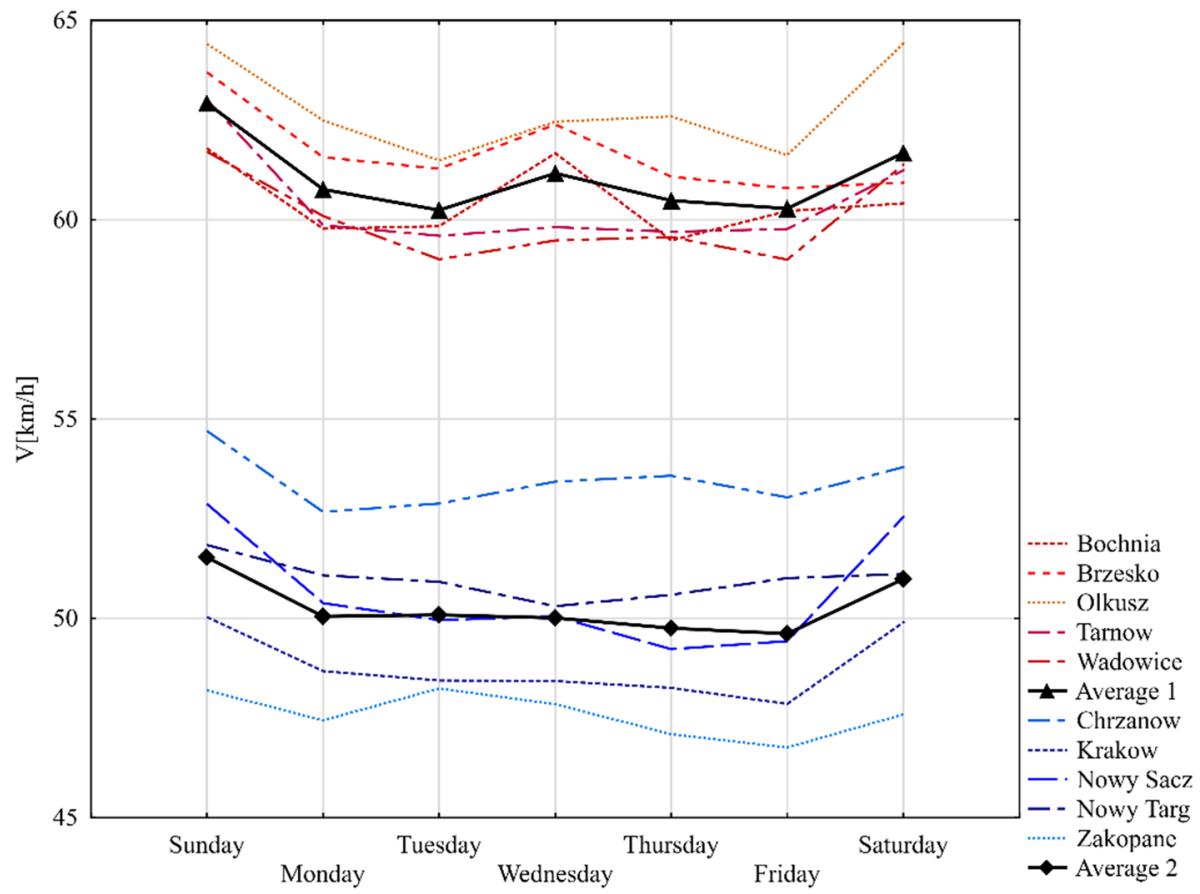

Fig. 9 Average ambulance speeds for selected cities of the voivodship, grouped by day of week 


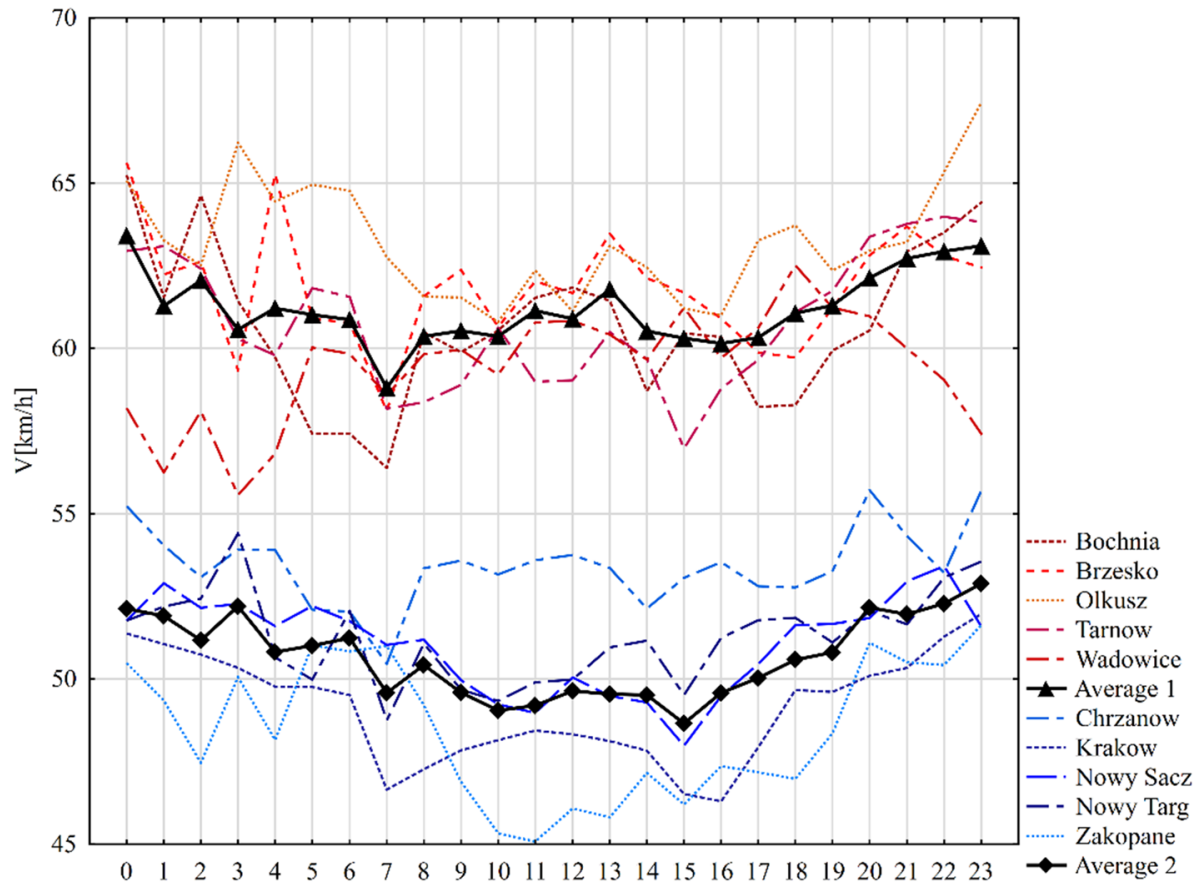

Fig. 10 Average ambulance speeds for selected cities of the voivodship, grouped by hour

Table 4 Division of cities into two clusters for ambulances driving with emergency signal

\begin{tabular}{|c|c|c|c|}
\hline \multicolumn{2}{|l|}{ Cluster 1} & \multicolumn{2}{|l|}{ Cluster 2} \\
\hline \multicolumn{2}{|c|}{ Distance between clusters } & \multicolumn{2}{|l|}{10.79} \\
\hline City & $\begin{array}{l}\text { Distance from the } \\
\text { center of concentra- } \\
\text { tion }\end{array}$ & City & $\begin{array}{l}\text { Distance from the } \\
\text { center of concentra- } \\
\text { tion }\end{array}$ \\
\hline Brzesko & 0.846 & Krakow & 1.505 \\
\hline Tarnow & 0.767 & Nowy Sacz & 0.818 \\
\hline Wadowice & 1.124 & Nowy Targ & 0.811 \\
\hline Olkusz & 1.782 & Zakopane & 2.745 \\
\hline Bochnia & 0.870 & Chrzanow & 3.175 \\
\hline
\end{tabular}

In the case of the agglomeration method, the Ward agglomeration method and the Euclidean distance measure were selected. The results of the conducted tests confirmed the visual division of cities into two groups and the outcome of the k-means algorithm (Fig. 11).

The results of k-means cluster analysis and the agglomeration tree for vehicles traveling without signals show a similar division of cities as for vehicles moving with signals on (compare Figs. 11 and 12, Tables 4 and 5). The only difference is Nowy Targ, which was classified as a city with a higher average ambulance speed, as is confirmed by descriptive statistics (Table 2). 
Tree diagram

Ward's method

Euclidean distance

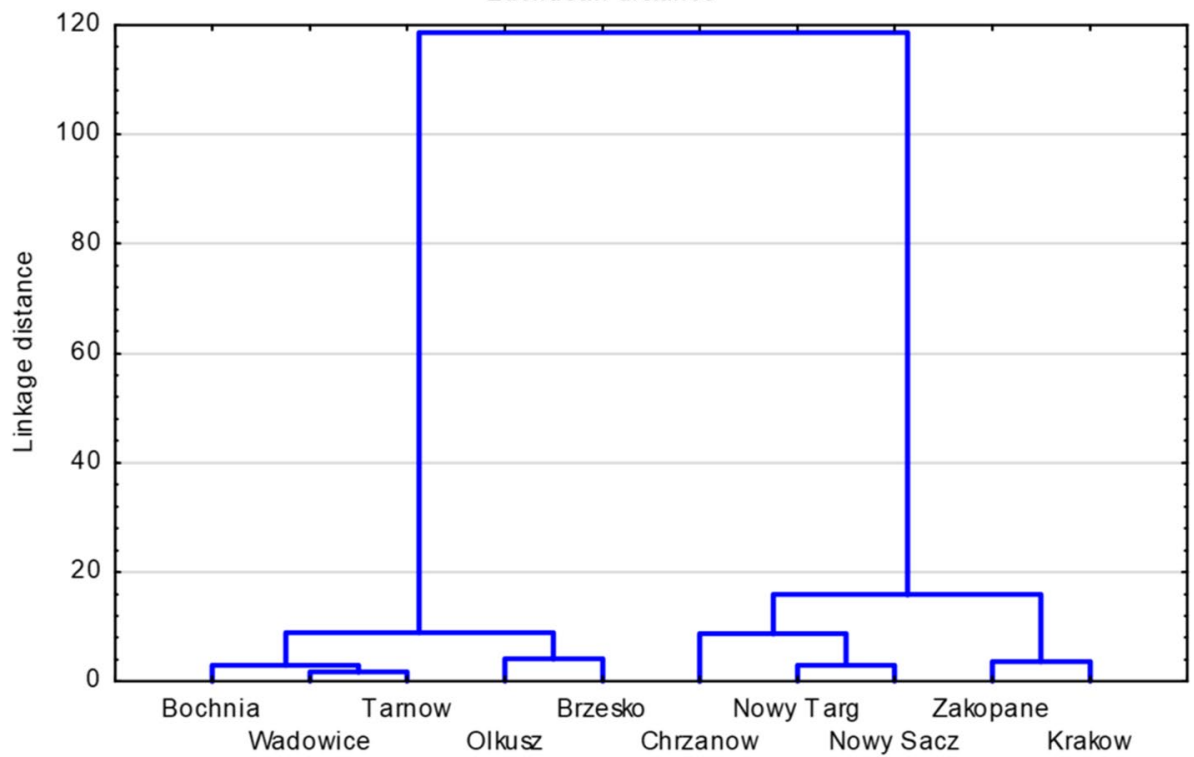

Fig. 11 Agglomeration tree division of towns for vehicles moving with emergency signals

Tree diagram

Ward's method

Euclidean distance

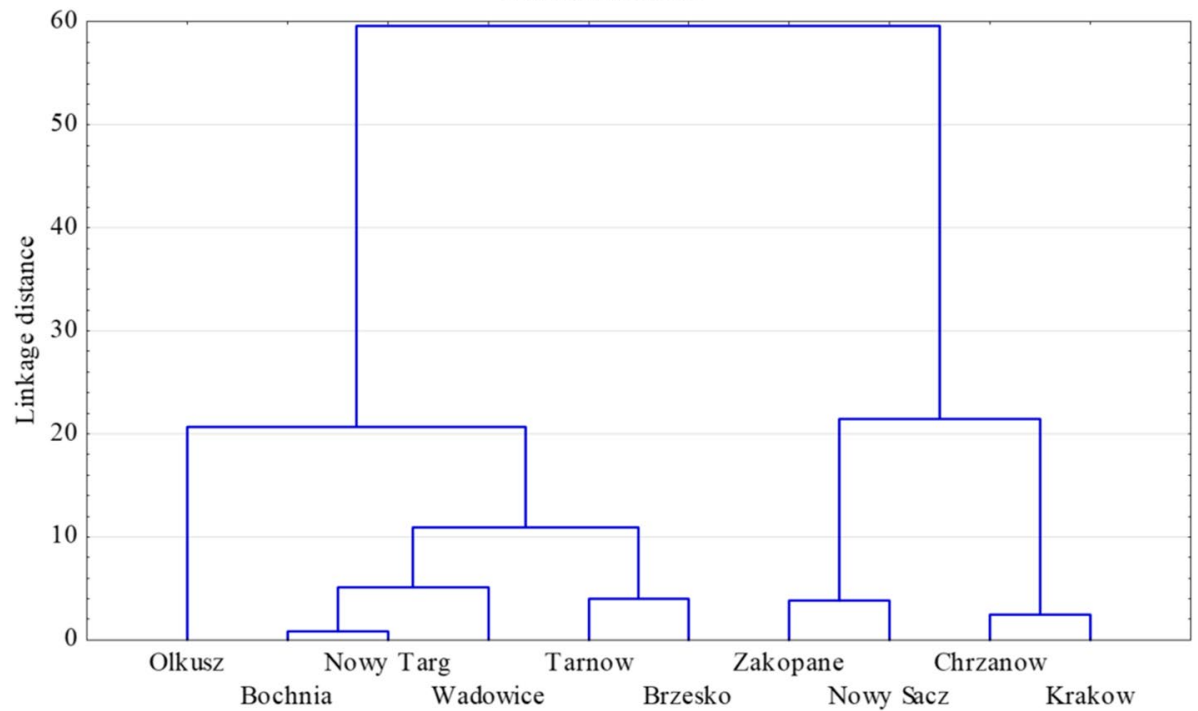

Fig. 12 Division of cities into two clusters for ambulances driving without emergency signals 
Table 5 Two-cluster division of cities for vehicles moving without an emergency signal

\begin{tabular}{|c|c|c|c|}
\hline \multicolumn{2}{|l|}{ Cluster 1} & \multicolumn{2}{|l|}{ Cluster 2} \\
\hline \multicolumn{2}{|c|}{ Distance between clusters } & \multicolumn{2}{|l|}{7.25} \\
\hline City & $\begin{array}{l}\text { Distance from the center of } \\
\text { concentration }\end{array}$ & City & $\begin{array}{l}\text { Distance from the } \\
\text { center of concentra- } \\
\text { tion }\end{array}$ \\
\hline Brzesko & 1.047 & Krakow & 2.593 \\
\hline Tarnow & 0.891 & Nowy Sacz & 1.645 \\
\hline Wadowice & 2.450 & Zakopane & 3.007 \\
\hline Olkusz & 4.533 & Chrzanow & 2.108 \\
\hline Bochnia & 1.689 & & \\
\hline Nowy Targ & 1.570 & & \\
\hline
\end{tabular}

Table 6 Ambulance speed statistics depending on road type and city cluster

\begin{tabular}{|c|c|c|c|c|c|c|c|c|}
\hline \multirow[t]{2}{*}{ Road type } & \multicolumn{4}{|c|}{ Cluster 1} & \multicolumn{4}{|c|}{ Cluster 2} \\
\hline & $\operatorname{Road} \%$ & Mean & Median & SD & Road \% & Mean & Median & $\mathrm{SD}$ \\
\hline Motorway & 1.94 & 114.32 & 122.00 & 27.44 & 0.44 & 114.81 & 119.00 & 21.41 \\
\hline Expressway & - & - & - & - & 18.80 & 54.58 & 54.00 & 25.70 \\
\hline $\begin{array}{l}\text { Main road of accel- } \\
\text { erated traffic }\end{array}$ & 6.64 & 57.74 & 58.00 & 28.10 & 30.75 & 55.92 & 56.00 & 24.36 \\
\hline Main road & 5.64 & 55.16 & 56.00 & 24.63 & 5.21 & 50.46 & 52.00 & 23.04 \\
\hline Collector road & 23.74 & 43.98 & 44.00 & 21.92 & 3.54 & 40.78 & 41.00 & 21.09 \\
\hline Local road & 48.91 & 27.69 & 24.00 & 18.84 & 39.63 & 29.24 & 27.00 & 17.76 \\
\hline Local access road & 13.13 & 31.35 & 28.00 & 18.49 & 1.64 & 26.64 & 24.00 & 16.81 \\
\hline
\end{tabular}

A very important observation at this point is that the adoption of one average speed characteristic for the entire voivodship is a mistake. In the case of estimating the speed of ambulances for some cities, this error may lead to erroneous conclusions that result in a few minutes' delay in the arrival time of ambulances. As research shows, these few minutes can significantly affect the prognosis of the injured person. The created model should be complex, including the city or at least the type of city (faster or slower group), day of week (weekday or weekend), and type of trip.

The next stage of research was to identify differences between the clustered cities (see Table 4). Three factors were considered: the road types in a given city cluster, the percentage distribution of the road types per cluster, as well as grouped speed values according to each road type (Table 6).

The percentage distribution of the road types showed large differences between two city groups. The greatest differences were observed for collector roads and main roads of accelerated traffic. The difference in the case of main roads of accelerated traffic was $24.11 \%$ (5.6\% for group 1 and $30.8 \%$ for group 2), where for collector roads it was $20.2 \%$ (23.7\% for group 1 and $3.5 \%$ for group 2). Additionally, it is worth mentioning that there were no expressways in group 1 .

Depending on the road type, the average speed of ambulances varied from $31.35 \mathrm{~km} / \mathrm{h}$ to $114.32 \mathrm{~km} / \mathrm{h}$ for the first group and from $26.64 \mathrm{~km} / \mathrm{h}$ to $114.81 \mathrm{~km} / \mathrm{h}$ for motorways in 
Table 7 A comparison of selected cities

\begin{tabular}{lclccc}
\hline Town name & Built-up area $\left[\mathrm{km}^{2}\right]$ & Building density & Road length $[\mathrm{km}]$ & Road count & Road density \\
\hline Zakopane & 84.156 & 0.016 & 283.105 & 2317 & 0.003 \\
Nowy Targ & 51.001 & 0.025 & 368.201 & 2585 & 0.007 \\
Chrzanow & 38.273 & 0.031 & 310.444 & 2479 & 0.008 \\
Bochnia & 29.833 & 0.045 & 255.862 & 2321 & 0.009 \\
Nowy Sacz & 57.518 & 0.054 & 579.165 & 5206 & 0.01 \\
Krakow & 326.382 & 0.064 & 3144.479 & 28,379 & 0.01 \\
Olkusz & 25.613 & 0.047 & 248.556 & 2237 & 0.01 \\
Tarnow & 72.306 & 0.055 & 783.846 & 6622 & 0.011 \\
Brzesko & 11.816 & 0.070 & 129.769 & 1354 & 0.011 \\
Wadowice & 10.530 & 0.070 & 120.496 & 1384 & 0.011 \\
\hline
\end{tabular}

the second group (Table 6). Slight differences between the mean values and the medians indicate a slight asymmetry of the speed distributions. The values of the standard deviations indicate the high variability of the speed of signaled (T) ambulances.

Local roads dominated in both groups of cities, representing $48.9 \%$ and $39.6 \%$ of all roads, where the average speeds are $27.7 \mathrm{~km} / \mathrm{h}$ and $29.2 \mathrm{~km} / \mathrm{h}$, respectively (see Table 6). What is more, local roads have a similar left-hand asymmetry and a similar value of standard deviation.

The first cluster of cities is characterized by a higher average speed for most types of roads (except for local roads and motorways). The difference in mean values ranges from about $4 \%$ for main roads of accelerated traffic to $16 \%$ for local access roads, with similar variability in the data as assessed by the standard deviation. In case of motorways $(1.9 \%$ and $0.44 \%$ of all roads), these speeds are similar $(114.3 \mathrm{~km} / \mathrm{h}, 114.8 \mathrm{~km} / \mathrm{h}]$.

\subsubsection{Correlations}

As the statistical analysis has shown, there are two general ambulance speed characteristics in the Lesser Poland voivodship. One of the research hypotheses adopted by the authors was that there is a statistically significant relationship between ambulance speed and local conditions, i.e. the size of a built-up area or the density of the road network of a particular city. Table 7 presents data from the analyzed cities, ordered according to the density of the road network. These data were then analyzed to find a correlation that would confirm the assumptions of the authors.

The Pearson's correlation coefficient was used to determine whether there is a dependence between ambulance speed and building density, building area, road length and road density.

The results presented in Table 8 show that at the standard significant level $(\mathrm{p} \leq 0.05)$ there is a statistically significant linear correlation between the speed of ambulances with lights/sirens and road density. Also, a nonlinear Spearman correlation coefficient was computed for the same group of parameters. Analysis shows that there is nonlinearity between ambulance speed and the size of the built-up area (see Table 9).

Pearson's correlation coefficient and Spearman's correlation coefficient confirmed the existence of a relationship between on-signal ambulance speed and building area (nonlinear correlation) and also with road density (linear correlation). Such relationships were not observed for the speed of ambulances without signals; this could be related to 
Table 8 Pearson's correlation coefficient

\begin{tabular}{llclc}
\hline $\begin{array}{l}\text { Type of ambulance } \\
\text { trip }\end{array}$ & Built-up area & Building density & Road length & Road density \\
\hline $\mathrm{S}$ & -0.555 & 0.504 & -0.439 & 0.641 \\
& $\mathrm{p}=0.096$ & $\mathrm{p}=0.137$ & $\mathrm{p}=0.205$ & $\mathrm{p}=0.046$ \\
$\mathrm{~T}$ & -0.282 & 0.376 & -0.170 & 0.572 \\
& $\mathrm{p}=0.429$ & $\mathrm{p}=0.284$ & $\mathrm{p}=0.638$ & $\mathrm{p}=0.084$ \\
\hline
\end{tabular}

Table 9 Spearman's correlation coefficient

\begin{tabular}{lllll}
\hline $\begin{array}{l}\text { Type of ambulance } \\
\text { trip }\end{array}$ & Built-up area & Building density & Road length & Road density \\
\hline $\mathrm{S}$ & -0.745 & 0.369 & -0.564 & 0.516 \\
$\mathrm{~T}$ & -0.503 & 0.369 & -0.309 & 0.491 \\
\hline
\end{tabular}

speed limits and traffic lights in cities, which do not concern ambulances using lights/ sirens.

Therefore, the created model should also contain information about the density of built-up areas. As building density increases, the speed of ambulances using lights/ sirens decreases non-linearly. Also, the model should contain information about road density. These values are positively correlated, and ambulance speed increases with higher values of these parameters.

A spatial representation of the analyzed parameters for individual cities shown on a map (Fig. 13).

The research hypothesis of the authors was that the model parameters are stable regardless of the analyzed city, day of the week, hour, etc. A detailed analysis of how the speed of ambulances is affected by the hour of the day, the day of the week and the month was used to confirm the assumptions. The average speed of signaled ambulances varies depending on the type of road on which it is traveling. Nevertheless, we can observe that in the case of different cities, the average speeds are different for each type of road. Therefore, we can assume that these speeds depend on additional factors. Based on the presented analysis, we can conclude that these factors are the size of the built-up area and road density (Table 7). The built-up area factor for the cities from the first cluster group is lower than $30 \mathrm{~km}^{2}$ (except for Tarnów) and is characterized by higher building density and a similar variation in total road length. Additionally, high correlation values with road density (Table 8) and built-up area (Table 9) seem to confirm this conclusion. After data analysis, the authors concluded that it is not possible to create one good-quality model for the whole voivodship. At least four models should be prepared: two for ambulance trips without signals in which data is divided into a faster and a slower group; and two for ambulance trips with signals. Models should have information about day of week, road density, and building area. 


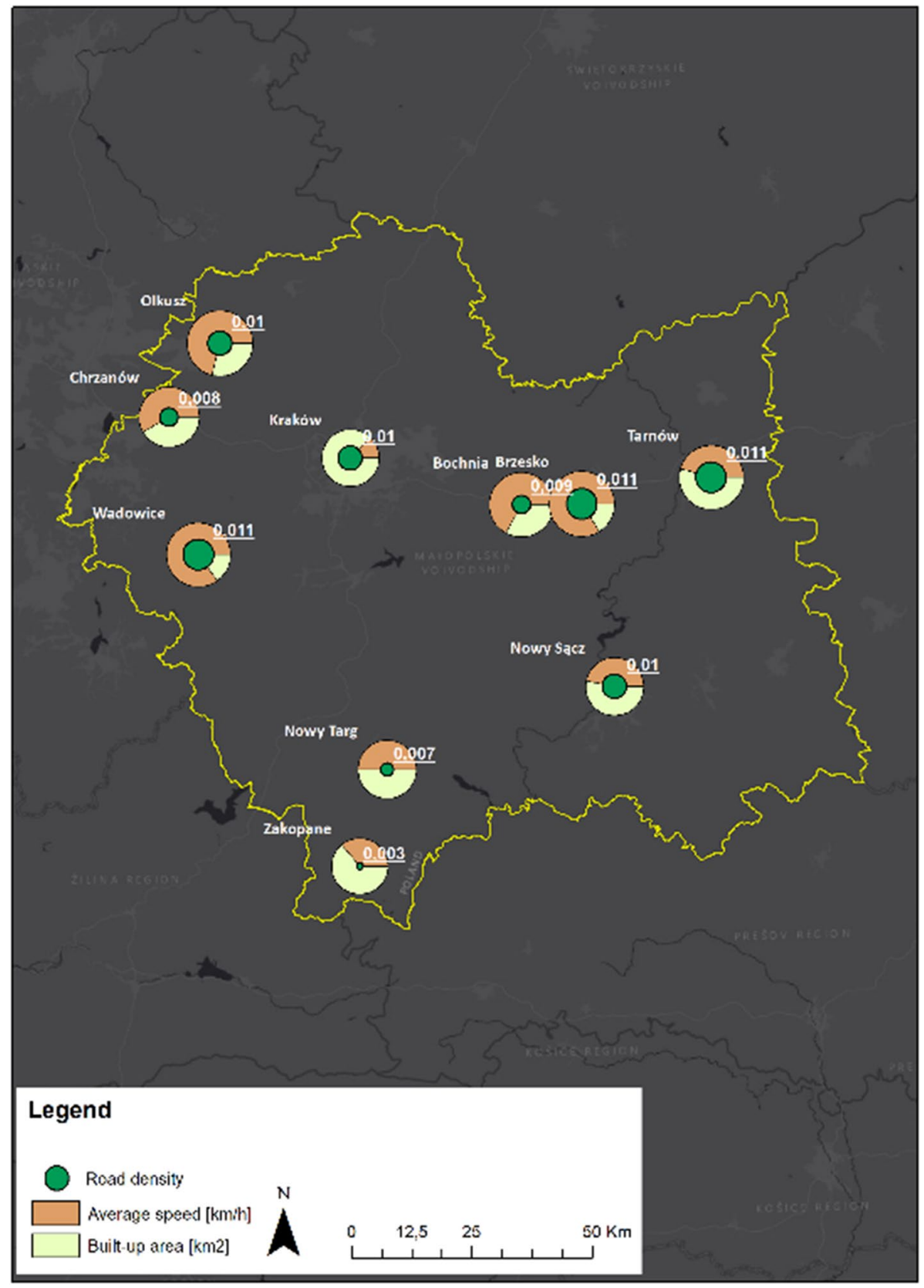

Fig. 13 Cities' division into two clusters for ambulances driving without emergency signals

\section{Coverage maps}

The time coverage map developed in the framework of this article consists of several components, all of which are described below; how to implement the solution and sample maps are also shown. 
The basic component in the creation of the time-coverage map was a rectangular computational grid. For the purposes of the research, it was assumed that the points of the grid are $250 \mathrm{~m}$ apart in urban areas, while $1000 \mathrm{~m}$ is considered sufficient in rural areas. The grid and all spatial data were oriented in the WGS84 coordinate system. In the event that the adopted spatial resolution is insufficient, the distance between nodes of the grid can be reduced. Additionally, selected points can be moved to other more important locations, and special points such as ambulance bases or hospitals can be added. This approach allows flexible representation of an analyzed area, with high-density classification in urban areas and low-density classification in areas where points are meaningless (e.g. lakes) [25].

The second data source used was the vector data sets available in OpenStreetMap. ${ }^{1}$ Maps created by this community have a high degree of relevancy and accuracy. The most important layer of data obtained from OSM was the road network, which formed the basis of the network analysis. These analyses were performed using the Open Source Routing Machine (OSRM) engine, taking into account the ambulance speed characteristics described in Sect. 2. The result of these calculations was a map of pre-measured travel times (PT) that shows travel times between any two points of the grid in both directions.

$$
P T=\left(P_{i} \times P_{j}\right)
$$

where $P_{i}, P_{j}$-i-th and j-th point of the grid, $P T(x, y)$-travel time between $P_{i}$ and $P_{y}$.

Coverage maps can be used in three ways, the first of which is the dynamic analysis of an ambulance's fluctuating range when moving around a certain area: the position of the ambulance $(\mathrm{X}, \mathrm{Y})$ connected to the nearest point of the calculation grid $\left(\mathrm{P}_{\mathrm{i}}\right)$ shows the time at which it will reach a given place on the map. The second case concerns the coverage of all available ambulances near the patient's location. To calculate this kind of coverage map (CM), the minimum travel time from all standby ambulances to each grid point Pi should be calculated.

$$
\boldsymbol{C M}\left(\boldsymbol{P}_{c}\right)=\operatorname{MIN}\left\{\boldsymbol{P T}\left(A_{1}, \boldsymbol{P}_{c}\right), \boldsymbol{P T}\left(A_{2}, \boldsymbol{P}_{c}\right), \ldots, P T\left(A_{n}, \boldsymbol{P}_{c}\right)\right\}
$$

where $A_{n}$ is the current location point of ambulance $i, P c$ is the closest grid point to the call point.

As a result, the calculated values for each grid point can be applied to the base map. Each point on the grid was assigned to the travel time of the nearest ambulance. An exemplary analysis is shown on the following map (Fig. 14).

The third way to use coverage maps is to simulate the coverage of the largest possible areas (e.g. voivodships) with a statutory ambulance arrival time (15 $\mathrm{min}$ in the city, $20 \mathrm{~min}$ in rural areas). An exemplary analysis for the entire voivodship is shown in Fig. 15. Blue shows where an ambulance is in 0-10 min range; green corresponds to 11-15 min; yellow shows 16-20 min; red and black denote more than $20 \mathrm{~min}$. It should also be added that black areas often correspond to national parks and mountain areas where ambulances are replaced by helicopter.

\section{Conclusions}

This article shows that estimating ambulance arrival time is a non-trivial issue that may result in underestimation or overestimation of ambulance travel times. These errors may adversely affect the decision of the dispatcher, who might send an ambulance from

\footnotetext{
${ }^{1}$ Map data copyrighted by OpenStreetMap contributors and available from https://www.openstreetmap.org
} 


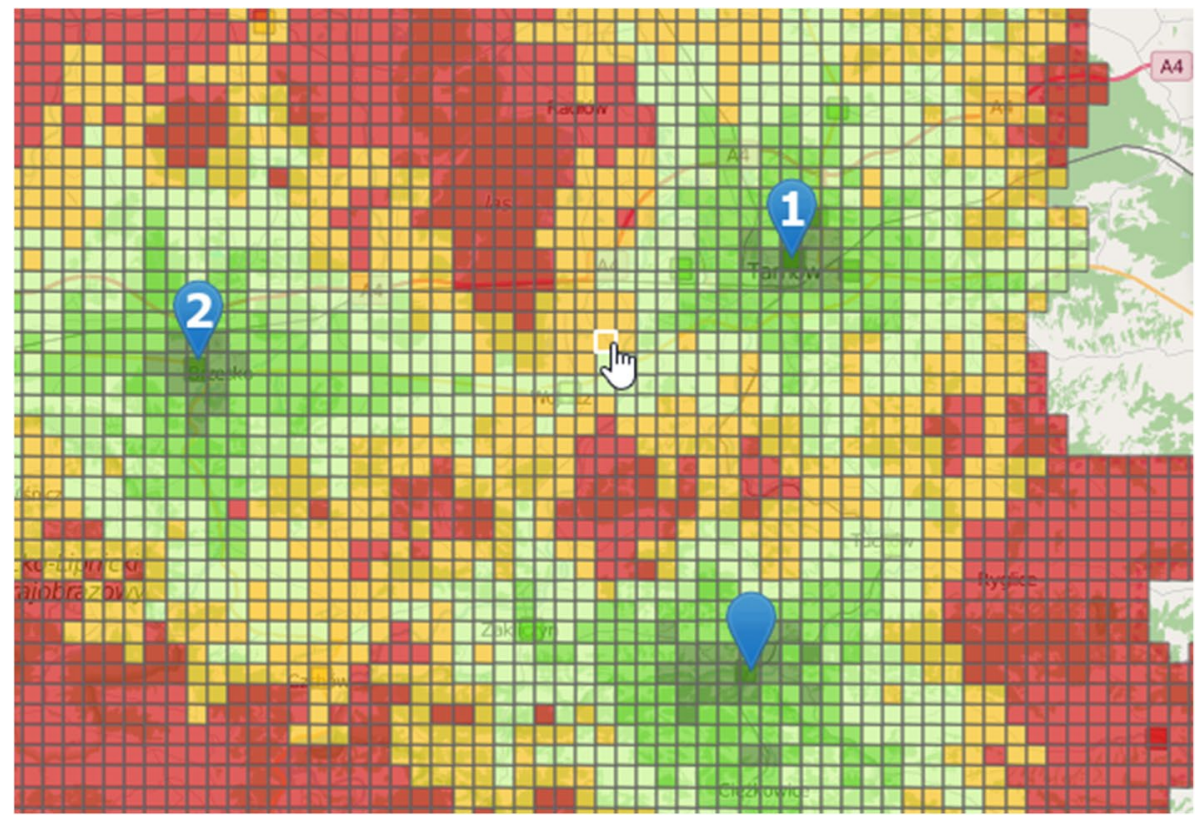

Fig. 14 Coverage map showing ambulances that will reach the call point in the shortest time

a non-optimal position to a given place. The presented studies also show that the speed at which ambulances move is a very local phenomenon. The case of Lesser Poland, as shown in the second chapter, shows that ambulances move at a constant speed regardless of the season. This makes it possible to refute the hypothesis that seasons affect ambulance arrival time. It is worth adding that the vast majority of the region is mountainous or hilly.

Another interesting observation is the relatively constant average speed of ambulances throughout the whole week. This means that ambulances travel at the same speed on weekdays and at weekends. This conclusion is interesting due to the fact that Lesser Poland is a popular tourist region. Moreover, many tourists choose a short weekend break in the mountains, which causes increased car traffic at the beginning and the end of the weekend.

The above conclusions are true when it is assumed that ambulances move with their lights/ sirens enabled. The difference between signaled and non-signaled ambulance trips is significant, as is shown in Table 2 and in Figs. 3, 5 and 6. The most surprising observation, however, is the lack of impact of rush hours on the speed of ambulances. The rush-hour phenomenon is clearly visible in the graph (Fig. 3) and is reflected in the lower average speed of ambulance trips without the use of lights/sirens. Ambulances on non-urgent trips are treated as regular road users.

The analysis of 300 million GPS records also showed that even in the case of such a small region as Lesser Poland $\left(15,183 \mathrm{~km}^{2}\right)$, which is approximately $4.8 \%$ of Poland's area, it cannot be assumed that the speed characteristics of ambulances will be the same across the entire country. Statistical analysis of ambulance speeds for the major cities of the voivodeship showed that the estimation of ambulance travel time should be based on two speed characteristics. The cities in both speed groups differ in terms of the type and method of space management; this is indicated by the correlation between ambulance speed, density of the road network, and the size of a built-up area. This correlation indicates a linear relationship between these factors, which confirms the division into two speed groups. 


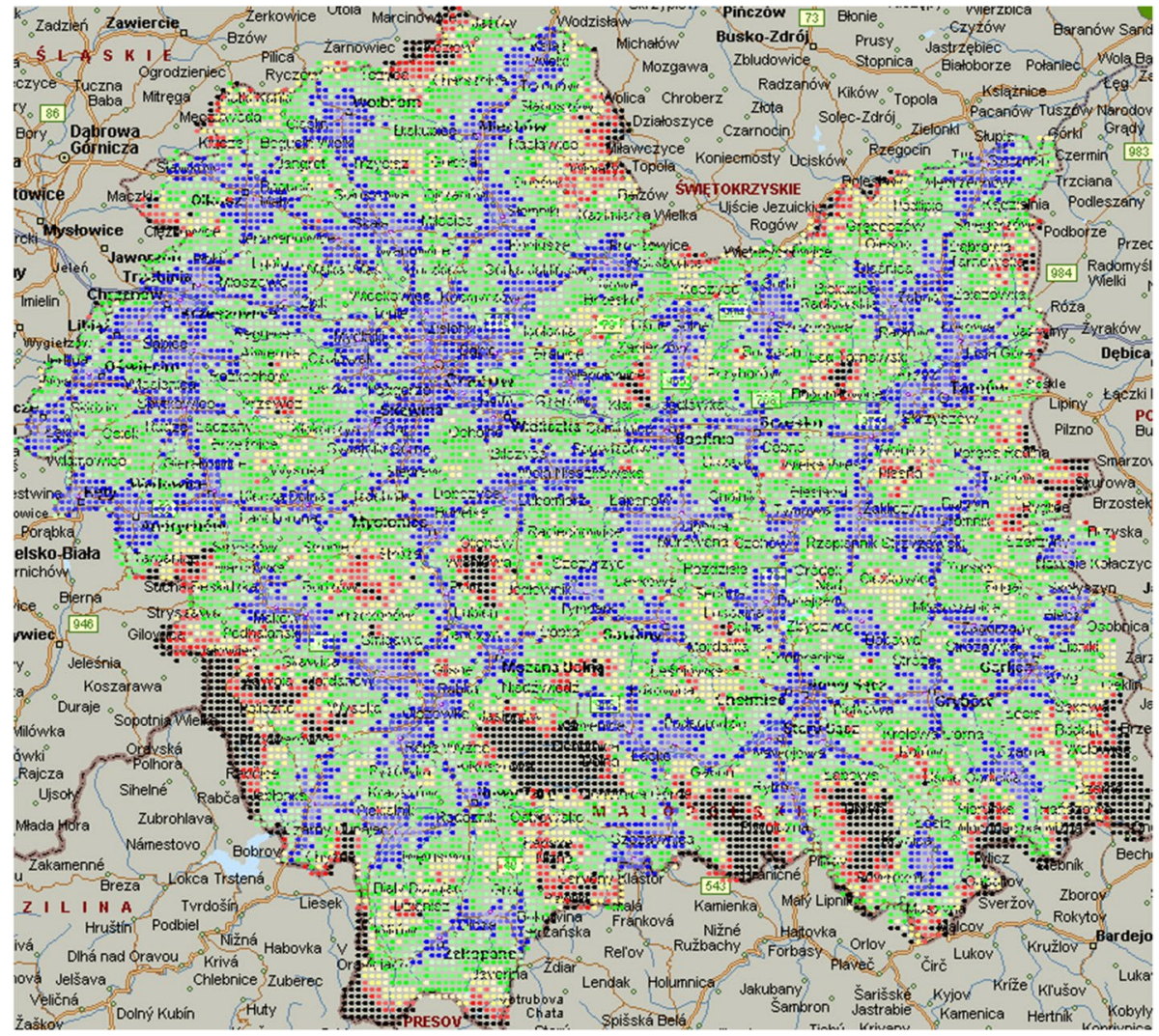

Fig. 15 Coverage map calculated for the entire voivodship

The prepared speed characteristics are also input data for the development of dynamic coverage maps. These maps show the ability of a given ambulance to reach its destination in less than $15 \mathrm{~min}$ (in the case of cities) or $20 \mathrm{~min}$ (in the case of rural areas). Only the real speed at which an ambulance moves makes sense, otherwise the ranges marked on such maps would be inaccurate. Based on the statistical analysis performed, we concluded that the speed differences in the analyzed aspects (day of the week, hour, month) of the signaled ambulance are minor and can be omitted in analysis so that the design of the speed model for the map's coverage purposes could be simplified. However, further research is needed to assess whether simplifying the model won't have a relevant impact on the accuracy of time-coverage maps. Furthermore, such maps allow ambulance fleets to be monitored under normal conditions or in the event of crises.

Data availability The data that support the findings of this study are available from Lesser Poland Voivodeship Office; however, restrictions apply to the availability of these data, which were used under license for the current study and so are not publicly available. Data are available from the authors upon reasonable request and with permission of Lesser Poland Voivodeship Office. 


\section{Declarations}

Competing interests The authors declare that they have no competing interests.

Open Access This article is licensed under a Creative Commons Attribution 4.0 International License, which permits use, sharing, adaptation, distribution and reproduction in any medium or format, as long as you give appropriate credit to the original author(s) and the source, provide a link to the Creative Commons licence, and indicate if changes were made. The images or other third party material in this article are included in the article's Creative Commons licence, unless indicated otherwise in a credit line to the material. If material is not included in the article's Creative Commons licence and your intended use is not permitted by statutory regulation or exceeds the permitted use, you will need to obtain permission directly from the copyright holder. To view a copy of this licence, visit http://creativecommons.org/licenses/by/4.0/.

\section{References}

1. The law of 8 September 2006 About State Emergency Medical Services (2006) Office of the Seimas, Poland

2. Aringhieri R, Bruni ME, Khodaparasti S, van Essen JT (2017) Emergency medical services and beyond: addressing new challenges through a wide literature review. Comput Oper Res 78:349-368

3. Yang B, Dai J, Guo C, Jensen CS, Hu J (2018) PACE: a PAth-CEntric paradigm for stochastic path finding. VLDB J 27(2):153-178

4. Li Y, Kotwal P, Wang P, Shekhar S, Northrop W (2019) Trajectory-aware lowest-cost path selection: a summary of results. In: Proceedings of the 16th international symposium on spatial and temporal databases, pp 61-69

5. Wang D, Zhang J, Cao W, Li J, Zheng Y (2018) When will you arrive? Estimating travel time based on deep neural networks. In: AAAI, pp 1-8

6. Li Y, Fu K, Wang Z, Shahabi C, Ye J, Liu Y (2018) Multi-task representation learning for travel time estimation. In: Proceedings of the 24th ACM SIGKDD international conference on knowledge discovery \& data mining, pp 1695-1704

7. Tlili T, Abidi S, Krichen S (2018) A mathematical model for efficient emergency transportation in a disaster situation. Am J Emerg Med 36(9):1585-1590

8. Poulton M, Noulas A, Weston D, Roussos G (2018) Modeling metropolitan-area ambulance mobility under blue light conditions. IEEE Access 7:1390-1403

9. Poulton MJ (2019) Modelling blue-light ambulance mobility in the London metropolitan area. University of London, Birkbeck

10. Bruni M, Beraldi P, Khodaparasti S (2018) A fast heuristic for routing in post-disaster humanitarian relief logistics. Transp Res Procedia 30:304-313

11. Hunt RC, Brown LH, Cabinum ES, Whitley TW, Prasad NH, Owens CF Jr, Mayo CE Jr (1995) Is ambulance transport time with lights and siren faster than that without? Ann Emerg Med 25(4):507-511

12. Brown LH, Whitney CL, Hunt RC, Addario M, Hogue T (2000) Dow arning 1 ights and sirens reduce ambulance response times? Prehosp Emerg Care 4(1):70-74

13. Ho J, Casey B (1998) Time saved with use of emergency warning lights and sirens during response to requests for emergency medical aid in an urban environment. Ann Emerg Med 32(5):585-588

14. Petzäll K, Petzäll J, Jansson J, Nordström G (2011) Time saved with high speed driving of ambulances. Accid Anal Prev 43(3):818-822

15. The TomTom Traffic Index (2019) TomTom International BV. https://www.tomtom.com/en_gb/traff ic-index/ranking/?country=PL.06.2019. Accessed 11 Aug 2021

16. Lam SSW, Nguyen FNHL, Ng YY, Lee VP-X, Wong TH, Fook-Chong SMC, Ong MEH (2015) Factors affecting the ambulance response times of trauma incidents in Singapore. Accid Anal Prev $82: 27-35$

17. Mahmood M, Thornes J, Pope F, Fisher P, Vardoulakis S (2017) Impact of air temperature on London ambulance call-out incidents and response times. Climate 5(3):61

18. Elliot AJ, Smith S, Dobney A, Thornes J, Smith GE, Vardoulakis S (2016) Monitoring the effect of air pollution episodes on health care consultations and ambulance call-outs in England during March/ April 2014: a retrospective observational analysis. Environ Pollut 214:903-911 
19. Macintyre HL, Heaviside C, Neal LS, Agnew P, Thornes J, Vardoulakis S (2016) Mortality and emergency hospitalizations associated with atmospheric particulate matter episodes across the UK in spring 2014. Environ Int 97:108-116

20. Stedman JR (2004) The predicted number of air pollution related deaths in the UK during the August 2003 heatwave. Atmos Environ 38(8):1087-1090

21. Henderson SG, Mason AJ (2000) BartSim: a tool for analysing and improving ambulance performance in Auckland, New Zealand. In: Proceedings of the 35th annual conference of the operational research society of New Zealand, Wellington, New Zealand, pp 57-64

22. Simic D, Simic S (2012) Hybrid artificial intelligence approaches on vehicle routing problem in logistics distribution. Hybrid Artif Intell Syst Pt I 7208:208-220

23. Bernas M, Wisniewska J (2013) Quantum road traffic model for ambulance travel time estimation. J Med Inform Technol 22:257-264

24. Sasaki S, Comber AJ, Suzuki H, Brunsdon C (2010) Using genetic algorithms to optimise current and future health planning-the example of ambulance locations. Int J Health Geogr 9(1):4

25. Piórkowski A (2018) Construction of a dynamic arrival time coverage map for emergency medical services. Open Geosci 10(1):167-173

26. Peleg K, Pliskin JS (2004) A geographic information system simulation model of EMS: reducing ambulance response time. Am J Emerg Med 22(3):164-170

27. Shuib A, Zaharudin ZA (2010) Framework of TAZ_OPT Model for ambulance location and allocation problem. World Acad Sci Eng Technol 72:924-929

28. Kamadjeu R, Tolentino H (2006) Web-based public health geographic information systems for resources-constrained environment using scalable vector graphics technology: a proof of concept applied to the expanded program on immunization data. Int J Health Geogr 5(1):24

29. Diller G-P, Kempny A, Piorkowski A, Grübler M, Swan L, Baumgartner H, Dimopoulos K, Gatzoulis MA (2014) Choice and competition between adult congenital heart disease centers: evidence of considerable geographical disparities and association with clinical or academic results. Circ: Cardiovasc Qual Outcomes 7(2):285-291

30. McMeekin P, Gray J, Ford GA, Duckett J, Price CI (2014) A comparison of actual versus predicted emergency ambulance journey times using generic Geographic Information System software. Emerg Med J 31(9):758-762. https://doi.org/10.1136/emermed-2012-202246

31. Piórkowski A (2011) Mysql spatial and postgis-implementations of spatial data standards. EJPAU 14(1):03

32. St L, Wold S (1989) Analysis of variance (ANOVA). Chemom Intell Lab Syst 6(4):259-272

33. Kodinariya TM, Makwana PR (2013) Review on determining number of Cluster in K-Means Clustering. Int J 1(6):90-95

34. Wishart D (1969) 256. Note: an algorithm for hierarchical classifications. Biometrics 25:165-170

35. Burman P (1989) A comparative study of ordinary cross-validation, v-fold cross-validation and the repeated learning-testing methods. Biometrika 76(3):503-514

Publisher's Note Springer Nature remains neutral with regard to jurisdictional claims in published maps and institutional affiliations.

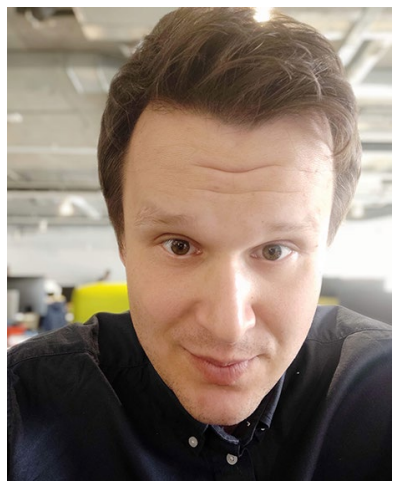

Michał Lupa holds a MSc in Applied Computer. Science combined with further $\mathrm{PhD}$ studies in cartography. He currently works at the Department of Geoinformatics and Applied Computer Science at AGH University of Science and Technology in Krakow. His main research interests include designing and implementing of geospatial data solutions in cartography, healthcare and remote sensing. 

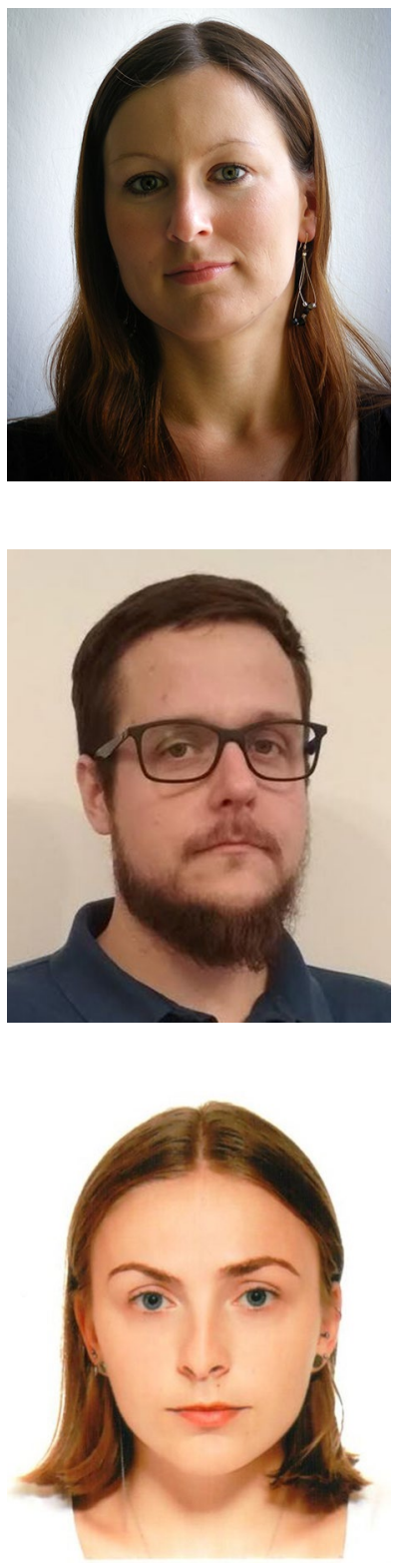

Monika Chuchro works at the Department of Geoinformatics and Applied Computer Science at the AGH University of Science and Technology in Krakow. She has completed her MS.c. degrees in Environmental Protection with additional studies in Computer Science and Data Analysis with further PhD studies in Geology. Her research interests covering data mining, time series analysis and data science and their application in environmental science.

Wojciech Sarlej PhD student at the Faculty of Geology, Geophysics and Environmental Protection in AGH University of Science and Technology in Krakow. His main scientific interests focus on the area of databases, GIS, ETL and BI processes.

Katarzyna Adamek Research assistant and a $\mathrm{PhD}$ student at the Department of Geoinformatics and Applied Computer Science at the AGH University of Science and Technology in Krakow, with Engineer's degree in Environmental Science followed by Master's degree in Mining and Geology. Her main scientific interests focus on remote sensing in geology, environmental sciences and general earth observations. 